\title{
Multiplicidade, dinâmicas e relações: sentidos da política para jovens universitários
}

\section{Cristina Satiê de Oliveira Pátaro'}

Frank Antonio Mezzomo²

Resumo: Investigamos os sentidos que jovens universitários atribuem à política, problematizando o modo como compreendem e se posicionam acerca dos debates e da participação na vida pública. Os resultados, obtidos a partir da análise de entrevista semiestruturada conduzida junto a 14 estudantes, evidenciam a multiplicidade de sentidos, dinâmicas e relações que permeiam o olhar sobre a política, o que nos leva a questionar uma ideia de linearidade e racionalidade na constituição do sujeito político, e a compreender as relações entre juventude e política para além de noções dicotômicas e essencializadas.

Palavras-chave: Jovens. Política. Universidade.

Multiplicity, dynamics and relations: meanings of politics for youth university students

1 Programas de Pós-Graduação Interdisciplinar Sociedade e Desenvolvimento (PPGSeD), de História Pública (PPGHP) e do Mestrado Profissional em Ensino de História (ProfHistória) da Universidade Estadual do Paraná (UNESPAR) - Campo Mourão - Brasil - Bolsista Produtividade pela Fundação Araucária - cristina.pataro@unespar.edu.br

2 Programas de Pós-Graduação Interdisciplinar Sociedade e Desenvolvimento (PPGSeD), de História Pública (PPGHP) e do Mestrado Profissional em Ensino de História (ProfHistória) da Universidade Estadual do Paraná (UNESPAR) - Campo Mourão - Brasil - frankmezzomo@gmail.com 
Abstract: We investigate the meanings that youth university students attribute to politics, problematizing how they understand and position themselves both on debates and participation in public life. The results, obtained from a semi-structured interview conducted with 14 young students, show the multiplicity of meanings, dynamics and relationships that permeate the view on politics, which leads us to question a view of linearity and rationality in the constitution of the political subject, and to understand the relations between youth and politics beyond the dichotomous and essentialized notions.

Keywords: Young people. Politics. University.

\section{Introdução}

Na última década, o Brasil tem presenciado uma onda crescente de manifestações políticas em diversos espaços e de diferentes formas, de modo mais ou menos organizado, protagonizadas por jovens, os quais vêm ganhando visibilidade no cenário público ao expressarem suas insatisfações, denunciarem aspectos e estruturas da sociedade, e levantarem bandeiras que abrangem um amplo espectro de pautas de natureza econômica, social, moral e de orientações político-ideológicas bastante distintas.

Diante disso, parece-nos evidente que, na atualidade, os jovens brasileiros estão presentes no cenário das disputas políticas e dos debates acerca do bem comum. Ao mesmo tempo, esta constatação leva-nos à necessária problematização das dicotomias e estereótipos que em geral emergem quando tematizamos as relações entre juventude e política: por um lado, os jovens tidos como apáticos, distanciados e descrentes da vida e das ações políticas; por outro lado, a juventude como grupo social naturalmente voltado para a transformação, a renovação e a militância. Ainda, o que podemos verificar é a ausência do que poderia ser visto como uma cultura política juvenil homogênea e associada, de antemão, a perspectivas de esquerda ou de direita, de emancipação ou de conservadorismo, já que as manifestações recentes abarcam uma multiplicidade de pautas, compreensões e posicionamentos, em que os sujeitos expressam diferentes formas de participação, motivação e graus de engajamento.

Este cenário justifica nossa indagação para o modo como os jovens vêm compreendendo e significando a dimensão política, em busca de investigar, de forma mais aprofundada, quais as dinâmicas e relações implicadas nessa complexa trama que envolve juventude e política. Assim, neste artigo, temos como 
objetivo analisar os sentidos que jovens universitários atribuem à política, na intenção de problematizar como esses sujeitos, que vivenciaram uma trajetória formativa no Ensino Superior, vêm compreendendo e se posicionando acerca dos debates e da participação na vida pública.

Entendemos, em nosso texto, que a dimensão política não se restringe às práticas institucionalizadas, hierarquizadas e/ou vinculadas ao Estado, mas abrange diversas manifestações e estratégias - redes sociais, fóruns, participação em coletivos, entre outros - por meio das quais é possível travar os debates acerca dos princípios e valores que devem reger a vida comum, em um movimento no qual as esferas individual e coletiva estão imbricadas e se (re)compõem mutuamente (Castro, 2015; 2016; Mayorga, 2017; Müxel, 1997; Boghossian; Minayo, 2009).

Entretanto, cabe destacar que nosso foco recai não propriamente sobre os debates que tratam de uma definição de política, mas sobre o modo como os próprios sujeitos a significam e quais os sentidos que a ela atribuem. Portanto, em conformidade com abordagens defendidas por teóricos como Boltanski $(2014,2017)$ e Latour (2012), a construção de nossa pesquisa parte do olhar dos indivíduos, dos atores, em vista de compreender a dinâmica dos laços sociais implicados, em nosso caso, na dimensão política, sem deixar de lado os aspectos estruturantes da sociedade que influenciam e se articulam às subjetividades. Ainda de acordo com esta perspectiva, a investigação acerca das ações humanas deve contemplar as incertezas que as caracterizam, o que nos leva a considerar que as trajetórias e compreensões dos jovens pesquisados são constituídas tanto pelas intencionalidades quanto pela imprevisibilidade, pelo devir, tão próprios do mundo humano e social (Boltanski, 2017). Trata-se, assim, de problematizar o modo como os jovens universitários compreendem e lidam com a dimensão pública, a coletividade, bem como com as disputas travadas no processo de definição de princípios e valores que devem ser comuns a todos, em vista de revelar os múltiplos fatores que estão imbricados nessa dinâmica, sem cair na dicotomia entre sujeito e contexto social (Mayorga, 2013).

\section{Metodologia}

Participaram da investigação 14 jovens universitários dos cursos de Licenciatura em Geografia e História de diferentes campi da Universidade Estadual do Paraná - Unespar (Campo Mourão, Paranaguá, Paranavaí e União da Vitória), conforme quadro a seguir: 
Tabela 1: Jovens participantes da investigação

\begin{tabular}{|l|l|l|l|l|}
\hline Nome & Idade & Cor/etnia & Curso de Graduação & Campus da Unespar \\
\hline Andréia & 26 anos & Branca & História & Paranavaí \\
\hline Flávio & 23 anos & Branco & Geografia & Paranavaí \\
\hline Beatriz & 21 anos & Branca & História & Campo Mourão \\
\hline Gustavo & 22 anos & Branco & Geografia & Campo Mourão \\
\hline Juliana & 25 anos & Branca & Geografia & União da Vitória \\
\hline Janaína & 21 anos & Parda & Geografia & Paranavaí \\
\hline Luiza & 22 anos & Branca & História & União da Vitória \\
\hline Lauro & 21 anos & Pardo & História & Paranavaí \\
\hline Rodrigo & 28 anos & Negro & História & Paranaguá \\
\hline Rafael & 26 anos & Branco & História & Paranaguá \\
\hline Sabrina & 22 anos & Branca & Geografia & Campo Mourão \\
\hline Vitória & 21 anos & Branca & Geografia & União da Vitória \\
\hline Vivian & 21 anos & Branca & História & Campo Mourão \\
\hline Wagner & 22 anos & Branco & História & União da Vitória \\
\hline
\end{tabular}

Fonte: Dados da pesquisa.

Os dados foram coletados em entrevista semiestruturada conduzida individualmente durante os meses de outubro e novembro de 2017, na ocasião em que os estudantes cursavam o último ano da licenciatura, já tendo vivenciado a maior parte da trajetória formativa no Ensino Superior. O roteiro de entrevista contemplava quatro blocos de questões, abordando temáticas relativas à vida cotidiana do jovem, às compreensões acerca da religião, da política e, por fim, as impressões e experiências relacionadas ao curso de Graduação ${ }^{3}$. Os estudantes participaram voluntariamente da pesquisa, mediante

3 Os dados aqui analisados foram coletados por ocasião de investigação mais ampla realizada pelo Grupo de Pesquisa Cultura e Relações de Poder, contando com apoio financeiro do CNPq e da Fundação Araucária, com o objetivo de analisar a constituição das identidades de jovens universitários de cursos de Licenciatura, na interface com a política e a religião. Os jovens entrevistados estiveram envolvidos em etapas anteriores da referida investigação em 2014 e em 2016, ocasião em que cursavam, respectivamente, o primeiro e o terceiro anos da Graduação. Os dados coletados nas etapas iniciais, aplicados por meio de questionário online, subsidiaram a definição dos estudantes que participaram das entrevistas em 2017. A pesquisa foi submetida e aprovada pelo Comitê de Ética em Pesquisa da Unespar, campus de União da Vitória, sob o Protocolo 72104082014, Parecer n. 19/2014. 
assinatura de Termo de Consentimento Livre e Esclarecido, mantendo-se o sigilo e anonimato das informações, sendo que os nomes mencionados no texto são fictícios.

Todos os participantes eram solteiros e estudantes de período noturno, exercendo algum tipo de atividade remunerada no período diurno, em tempo integral ou parcial - seja em empregos formais, informais, estágio ou recebendo bolsa de algum programa institucional da Universidade (Iniciação Científica ou Iniciação à Docência). Quanto à escolaridade dos familiares, 39\% dos pais e mães não possuíam o Ensino Fundamental completo, e apenas 17\% tiveram acesso ao Ensino Superior.

Cabe destacar que os campi da Unespar aos quais os jovens estiveram vinculados estão localizados em municípios de médio ou grande porte, sendo que o maior deles (Paranaguá) possui cerca de 150 mil habitantes e o menor (União da Vitória) conta com uma população estimada em 57 mil (IBGE Cidades, 2018). No entanto, a maioria dos jovens não residia no mesmo município de instalação do campus universitário, tendo que se deslocar diariamente de cidades menores para estudar e/ou trabalhar.

A interpretação dos dados se deu com base na metodologia de Análise de Conteúdo (Bardin, 2011), com a leitura flutuante de todos os protocolos das entrevistas, buscando-se, na exploração do material, identificar as unidades de registro, as recorrências e especificidades nas compreensões dos participantes. Nesse sentido, foram selecionados todos os trechos dos protocolos que traziam indícios acerca dos significados atribuídos pelos sujeitos à política, de modo que a análise não se restringiu apenas a algumas das questões do roteiro, mas à argumentação e impressões dos estudantes ao longo de toda a entrevista. Por meio de tal procedimento, na (re)organização das unidades de registro, foram identificadas cinco categorias temáticas que expressam os sentidos atribuídos à política pelos jovens universitários, as quais aparecem de modo articulado nas narrativas construídas pelos participantes. Assim, as categorias temáticas que subsidiam nossa análise não podem ser vistas de modo estanque e isolado, e nem como linhas de raciocínio que se excluem mutuamente - ainda que abarquem contradições, como veremos -, mas como expressões integradas de um mosaico de sentidos compartilhado entre diferentes sujeitos e, ainda, presente - em parte ou no todo - no raciocínio de um mesmo entrevistado. 


\section{Análise dos dados}

A trajetória formativa dos jovens participantes da pesquisa foi marcada, desde o ingresso na Unespar, por diferentes eventos políticos que movimentaram o cenário nacional e estadual. Desde a disputa eleitoral para a presidência em 2014 - marcada por forte polarização entre os apoiadores dos candidatos do PSDB, Aécio Neves, e do PT, Dilma Rousseff, a qual saiu exitosa no referido pleito -, até o impeachment, em 2016, da presidente eleita e a posse de seu vice, Michel Temer, o país vivenciou uma série de protestos e manifestações nas ruas, nas mídias e em outros espaços públicos e privados. Já no Paraná, os anos de 2015 e 2016 foram marcados por greves e paralisações dos servidores, sobretudo dos docentes da Educação Básica e do Ensino Superior, em oposição a uma série de medidas - envolvendo inclusive o plano de previdência dos servidores e a autonomia universitária -, tomadas pelo então governador Beto Richa (PSDB), que em 2015 iniciava seu segundo mandato. Além disso, em 2016, instituições de ensino públicas - escolas de Ensino Médio e universidades - de todo o país foram ocupadas por estudantes, em protestos contra a situação precária da educação no Brasil, em especial as medidas adotadas pelo Governo Federal referentes à Reforma do Ensino Médio e à Emenda Constitucional do Teto de Gastos Públicos (Gohn, 2018; Pereira; Allan, 2016; Jinkings; Doria; Cleto, 2016). Vale lembrar, ainda, que há uma particularidade geracional que marca a trajetória de vida destes jovens que, por terem nascido em período posterior à redemocratização do país, puderam vivenciar e ter contato com os espaços e mecanismos de participação que foram possibilitados pela Constituição de 1988 (Corrochano; Dowbor; Jardim, 2018).

Assim, a análise e interpretação dos dados da pesquisa devem ter presentes tais elementos, que permeiam as compreensões dos jovens e influenciam suas vivências, trajetórias e, em última instância, os sentidos que atribuem à política. Cientes de tais considerações, passemos à discussão de cada uma das categorias temáticas construídas.

\section{Política enquanto dimensão pública e coletiva}

A categoria temática descrita no quadro a seguir foi identificada nos relatos de 11 dos 14 jovens de nossa pesquisa: 
Quadro 1: Política em sua dimensão pública e coletiva - sentidos e narrativas dos jovens

\begin{tabular}{|l|l|}
\hline Descrição & Trechos das narrativas \\
\hline Esta categoria temática associa a política & \\
a uma dimensão pública e coletiva, & \\
entendendo-a como um elemento que & "Política é tudo que é público, então, toda a \\
estrutura a sociedade, e que, portanto, está & discussão pública é política. [...] A política é \\
presente em todos os espaços, devendo & tudo que trata do bem comum, da população \\
voltar-se ao bem comum, a toda a população. & em geral, do cidadão, tudo o que envolve \\
A política é o espaço de reivindicação & todos os cidadãos, todo mundo que tá aí \\
de direitos, com vistas à cidadania e à & vivendo no Brasil e é cidadão brasileiro está \\
transformação para a melhoria da sociedade. & influenciado pela política, querendo ou \\
$\begin{array}{l}\text { Por estar relacionada a uma dimensão } \\
\text { pública e coletiva, permeia todos os espaços }\end{array}$ & não, gostando ou não. Ela faz parte de tudo." \\
e instituições - o município, o bairro, o país, & (Rodrigo, História, Paranaguá). \\
a universidade -, influenciando diretamente & \\
a vida e o cotidiano dos jovens. Além disso, & "Meu bairro é gerado em política, a \\
deve ter uma perspectiva universalizante, & universidade é política, tudo, eu acho que \\
abarcando as necessidades e as demandas & basicamente tudo é política." (Luiza, História, \\
de todas as pessoas. Com base nessa & União da Vitória). \\
compreensão, emerge um desejo expresso & \\
por alguns jovens de que a política contribua & "Política é o que realmente tem a capacidade \\
para a ampliação de direitos e a consequente & de transformar o nosso meio, se a gente \\
transformação da sociedade. Assim, por & conseguir se apropriar dela a gente tem uma \\
meio da política, é possível o exercício & ferramenta super importante para conseguir \\
da cidadania e da democracia, em uma & mudar nossa realidade." (Wagner, História, \\
perspectiva que alguns dos participantes & União da Vitória). \\
compreendem como utópica, na medida & \\
em que vislumbram a possibilidade de & \\
construção de uma sociedade diferente. & \\
\hline
\end{tabular}

Fonte: Dados da pesquisa.

Ao associarem a política à dimensão pública e coletiva, à democracia e ao bem comum, revela-se uma concepção clássica do termo, retomando ideias já presentes nas reflexões de filósofos gregos. Para Aristóteles, por exemplo, a política está para a dimensão coletiva assim como a moral está para a dimensão pessoal, de modo que: "Não entra no plano da Política determinar o que pode convir a cada indivíduo, mas sim o que convém à pluralidade" (Aristóteles, 1998: 59). Em ambos os casos - tanto na dimensão coletiva quanto na dimensão pessoal -, as ações devem ser orientadas pela ética, de modo que política e ética devem atuar conjuntamente para a busca da felicidade dos cidadãos.

Esta perspectiva também serve de base para reflexões contemporâneas acerca da temática, como podemos constatar no trabalho de Hannah Arendt (2002, 2007). Esta autora privilegia o espaço público, comum a todos, como aquele em que se exerce ação política, e que envolve a pluralidade de 
opiniões, o diálogo e o debate de ideias. Todos devem ter, assim, a liberdade de atuar no espaço público, o direito de pertencer a uma comunidade politicamente organizada, o que só é possível por meio da ação conjunta. A política é, assim, coletiva, relacionada à busca pelos direitos e igualdade, ao discurso e à ação que se efetivam no encontro entre os seres humanos para compartilhar o mundo.

Esta é a lógica que parece orientar algumas das manifestações apresentadas pelos jovens da pesquisa. Nesta categoria temática, é a política, com base na ação coletiva, que permitiria uma ampliação de direitos e a transformação da sociedade, em vista de atender às necessidades e demandas de todos, indistintamente, concebendo um outro mundo utopicamente desejado. Vejamos:

A política é para ser correta, ela é para dar sustentabilidade para a população. Eu penso assim, aquela democracia, que o povo um dia ainda vai ter voz nesse mundo, e que quando ele tiver voz ele vai saber o que fazer. (Beatriz, História, Campo Mourão).

É a oportunidade de a gente lutar pelos direitos. (Flávio, Geografia, Paranavaí).

Ao mesmo tempo, o que podemos depreender desta mesma categoria é um entendimento de que "tudo é política", isto é, de que esta se faz presente em todos os espaços e instituições, em todas as relações estabelecidas entre as pessoas - sejam elas públicas ou privadas. Assim, conforme afirmam: "tudo, eu acho que basicamente tudo é política"; "ela é vigente, ela está em todo lugar". Tal concepção, por um lado, parece-nos apresentar uma ideia ampliada de que a política permeia todas as relações e o cotidiano de todas as pessoas - e não apenas dos políticos que ocupam os cargos representativos -, não estando restrita apenas aos espaços institucionais, a relações hierarquizadas ou às instâncias do Estado. Por outro lado, pode conduzir a uma ideia difusa de política, que venha a incorrer em seu esvaziamento, tendo em vista a dificuldade de identificar especificamente o lócus, as pautas e os processos envolvidos nos debates que envolvem as definições do bem comum, que estariam dispersos no cotidiano (Machado, 2013; Ferreira, 2004).

\section{Política, corrupção e interesses particulares}

O Quadro 2 apresenta os sentidos e alguns exemplos que constituem a segunda categoria temática, presente nos relatos de 13 jovens. 
Quadro 2: Política associada à corrupção e interesses particulares - sentidos e narrativas dos jovens

\begin{tabular}{|c|c|}
\hline Descrição & Trechos das narrativas \\
\hline $\begin{array}{l}\text { Nesta categoria temática, a política é valorada } \\
\text { negativamente, sendo associada a interesses } \\
\text { pessoais, favorecimento de grupos e corrupção. } \\
\text { Segundo esta compreensão, as pessoas que } \\
\text { se interessam pela política ou que passam a } \\
\text { integrar os organismos do Estado são, em sua } \\
\text { maioria, movidas por interesses pessoais, como } \\
\text { dinheiro, status e poder, de modo que a política } \\
\text { acabaria beneficiando sempre os mesmos } \\
\text { grupos, deixando de lado uma parcela da } \\
\text { população - em geral os mais vulneráveis. Ainda } \\
\text { neste entendimento, mesmo aqueles políticos } \\
\text { que inicialmente possuem boas intenções, } \\
\text { acabam se corrompendo e sendo absorvidos } \\
\text { pelo sistema, afinal, há uma engrenagem em } \\
\text { movimento, um funcionamento já estabelecido } \\
\text { que impossibilita qualquer ação que destoe desta } \\
\text { lógica corrupta e corporativa. Como decorrência } \\
\text { desta dinâmica de interesses, a política é } \\
\text { associada a uma prática baseada na troca de } \\
\text { favores, em uma lógica na qual aqueles que estão } \\
\text { no poder beneficiam seus apoiadores e acabam } \\
\text { por preterir - inclusive no acesso aos serviços } \\
\text { públicos - as pessoas e grupos que a eles não } \\
\text { se alinham. Por este motivo, ainda, alguns dos } \\
\text { estudantes - sobretudo aqueles que residem em } \\
\text { municípios menores - mencionam certo receio } \\
\text { na manifestação de ideias que possam a vir a } \\
\text { contrariar o establishment, já que esse tipo de } \\
\text { comportamento pode gerar represálias. }\end{array}$ & $\begin{array}{l}\text { "As pessoas mais pobres é as que mais } \\
\text { acabam sofrendo, enquanto os grandes, que } \\
\text { têm dinheiro, detentores do poder, são os } \\
\text { que mais são beneficiados com a política." } \\
\text { (Sabrina, Geografia, Campo Mourão). } \\
\text { “Todo mundo cansou de ouvir, só ouve } \\
\text { corrupção, corrupção, corrupção, preso, } \\
\text { delação etc. [...]. As coisas parecem tão } \\
\text { corruptíveis, porque mesmo quando a } \\
\text { pessoa entra com boas intenções, ela não } \\
\text { consegue se manter lá dentro, porque ela não } \\
\text { se adapta ao sistema que já está engrenado." } \\
\text { (Beatriz, História, Campo Mourão). }\end{array}$ \\
\hline
\end{tabular}

Fonte: Dados da pesquisa.

Quanto à concepção que associa política aos interesses particulares e à corrupção, é possível perceber que, com base em tal entendimento, os jovens adotam uma postura de afastamento - e até de repulsa - com relação a esta esfera, afinal, há uma percepção de que os organismos do governo estariam estruturados de modo a atender a interesses de pessoas e grupos específicos. Nessa categoria temática, a política a qual se referem os estudantes de nossa investigação está associada à institucionalidade do Estado, ao espaço formal, isto é, aos políticos que ocupam os cargos nas diferentes esferas de poder. A descrença com relação ao Estado manifestada pelos jovens pode ser entendida no encalço de uma desconfiança nas instituições, de um movimento de ocupação do espaço público pelas questões privadas, e, em última instância, da própria instabilidade da democracia na contemporaneidade (Castells, 2018; Bauman, 2000; 2008; Gohn, 2018). 
Ao analisar o cenário político dos últimos anos na Europa, Estados Unidos e também na América Latina - inclusive no Brasil -, Castells (2018: 12) verifica um movimento de ruptura na relação entre governantes e governados, que culmina no distanciamento entre a classe política e os cidadãos. A perda da confiança nos políticos, decorrente em parte da publicização dos escândalos e casos de corrupção, acaba por gerar uma descrença para com o próprio sistema. Deste modo, 0 autor sugere a existência de uma crise da democracia liberal, na qual há um questionamento da legitimidade da política, isto é, "o sentimento majoritário de que os atores do sistema político não nos representam”. Esta é a lógica que parece estar presente nestas narrativas dos jovens, que, ao falarem sobre a política, argumentam que "Todo mundo cansou de ouvir, só ouve corrupção", uma vez que "Todo mundo que está ali acaba se corrompendo".

A este entendimento, soma-se, ainda, a perspectiva que os jovens constroem acerca de uma das faces visíveis do Estado, que passa a ser entendido como seletivo e excludente ("os [...] detentores do poder são os que mais são beneficiados com a política"), proporcionando uma distribuição desigual dos direitos, e levando os estudantes a terem receio de se manifestar e de se envolver com questões políticas. Ao que parece, isso fica ainda mais claro tendo em vista que os estudantes da pesquisa residem em municípios de pequeno porte, nos quais há uma relação mais próxima com as instituições e representantes do poder formal:

Eu prefiro não me meter. (Juliana, Geografia, União da Vitória).

Não pode ficar se envolvendo muito [...] na minha cidade, eu acabo sendo um pouco mais oprimida. (Andréia, História, Paranavaí).

A pessoa precisa de saúde e acaba não tendo atendimento: "não vamos te ajudar porque você não me deu seu voto”. (Sabrina, Geografia, Campo Mourão).

Nesse sentido, podemos dizer que a máquina estatal adquire uma conotação próxima à ideia de polícia desenvolvida por Rancière $(1996,2006)$, entendida como responsável pela organização de poderes, pela distribuição hierárquica de lugares e funções, buscando legitimá-las, naturalizá-las e promovendo relações de opressão e exclusão. Assim, para além da dinâmica de disciplinarização dos corpos, a polícia atua como "uma regra de seu aparecer, uma configuração das ocupações e das propriedades dos espaços em que essas ocupações são distribuídas" (Ranciére, 1996: 42). Essa noção seria justamente oposta à noção de política, a qual, para Rancière, deve ser entendida como a interrupção das distribuições desigualitárias, por meio da revelação dos conflitos, em busca da igualdade (Rancière, 1996; 2006; Machado, 2013; Fair, 2009). Deste modo, segundo as narrativas dos jovens da pesquisa, o Estado, em lugar de atuar na 
busca pela igualdade, acaba por reforçar desigualdades e exercer certo poder coercitivo sobre a vida das pessoas, uma vez que está sob o comando de políticos que empreendem práticas corporativas e corruptas, interessados em benefícios pessoais e na manutenção de seus privilégios.

\section{Política como espaço de debate, manifestação de ideias e posicionamentos}

Quanto a esta categoria temática, 13 dos 14 jovens manifestaram uma perspectiva de política associada ao espaço de debates, ideias e posicionamentos, conforme apresentado no quadro a seguir:

Quadro 3: Política como espaço de debate, manifestação de ideias e posicionamentos - sentidos e narrativas dos jovens

\begin{tabular}{|c|c|}
\hline Descrição & Trechos das narrativas \\
\hline $\begin{array}{l}\text { Nessa compreensão, a política é associada à } \\
\text { manifestação pública de posicionamentos e } \\
\text { ideias, que expressam diferentes visões de } \\
\text { mundo, por vezes consoantes e, em outros } \\
\text { casos, contraditórias, conflitivas - e que, } \\
\text { portanto, entram em disputa. A política não } \\
\text { está limitada à esfera institucional, e está } \\
\text { presente até mesmo nas relações cotidianas } \\
\text { dos próprios estudantes. Os jovens entendem } \\
\text { que a política se efetiva nos discursos, nos } \\
\text { argumentos, nos debates, por meio dos quais } \\
\text { o sujeito pode influenciar os demais. Ao } \\
\text { mencionarem os posicionamentos políticos } \\
\text { e as diferentes visões de mundo implicadas, } \\
\text { referem-se com grande frequência ao debate/ } \\
\text { embate que se criou entre aquilo que entendem } \\
\text { por direita X esquerda. Nesse sentido, ao } \\
\text { narrarem acerca de suas compreensões } \\
\text { sobre a política, os participantes acabam } \\
\text { também se posicionando e reforçando a } \\
\text { polarização construída - embora, em alguns } \\
\text { casos, também discordem desta perspectiva } \\
\text { dicotômica. Por envolver o debate de ideias } \\
\text { e a disputa de posicionamentos, os jovens } \\
\text { também manifestam certo incômodo gerado } \\
\text { pela política em suas interações em diferentes } \\
\text { âmbitos, tanto no familiar quanto em outros } \\
\text { espaços. Nessa direção, falar sobre política é } \\
\text { muitas vezes tomado como sinônimo de brigas, } \\
\text { desentendimentos, conflitos, fazendo com que } \\
\text { alguns dos participantes acabem inclusive se } \\
\text { distanciando dos debates políticos. }\end{array}$ & $\begin{array}{l}\text { “Tem os atos políticos da vida: de falar, } \\
\text { de existir, de questionar, de dar aula, de } \\
\text { discutir com os amigos [...]. É existir como } \\
\text { ser político, como todo mundo existe, } \\
\text { dando minhas opiniões, tentando mover as } \\
\text { políticas de estado conforme essa minha } \\
\text { visão de mundo, votando e discutindo } \\
\text { sempre. [...] Essa ideia de fazer política é } \\
\text { mais ou menos por aí: tentar influenciar as } \\
\text { pessoas, tanto profissional, como professor, } \\
\text { quanto no pessoal." (Rodrigo, História, } \\
\text { Paranaguá). } \\
\text { "Eu pude reconhecer a esquerda muito mais } \\
\text { próxima ao meu cotidiano do que a direita. } \\
\text { Então, sendo o curso voltado ao pensamento } \\
\text { crítico, você passa a ter uma visão sobre } \\
\text { ações da direita e esquerda, você passa } \\
\text { analisar e compreender mesmo as coisas. E, } \\
\text { quando você compreende, você se posiciona." } \\
\text { (Lauro, História, Paranavaí). } \\
\text { "Hoje em dia, nessa questão de política e } \\
\text { corrupção, parece que o mundo se dividiu } \\
\text { entre direita e esquerda. [...] as pessoas } \\
\text { deixam de se falar por questões políticas, } \\
\text { por posicionamentos políticos [...]. Elas } \\
\text { brigam por isso, olham para você de cara } \\
\text { feia porque você segue tal movimento, tal } \\
\text { pensamento de algum partido." (Beatriz, } \\
\text { História, Campo Mourão). }\end{array}$ \\
\hline
\end{tabular}

Fonte: Dados da pesquisa. 
Na terceira categoria temática revelada, a política é vista como espaço do debate, da manifestação de ideias e de posicionamentos - que, na compreensão dos jovens, pode ocorrer tanto no espaço da política formal e institucional quanto nas relações cotidianas. Dois elementos merecem destaque em nossa análise: em primeiro lugar, a referência bastante recorrente à polarização entre direita e esquerda nos assuntos a respeito da política; em segundo, uma compreensão de que a política conduz ao conflito, às brigas e que, diante disso, muitos dos jovens preferem não apenas se abster, como se distanciar de tais discussões.

Para abordar o primeiro destes elementos - a dicotomia entre direita e esquerda -, entendemos ser adequado contextualizar as disputas políticas ocorridas no Brasil ao longo dos últimos anos. Antes, porém, vale uma ponderação, ainda que breve, acerca da utilização de tais categorias para a compreensão dos embates que hoje estão presentes no país. A despeito da polissemia, das dificuldades e das controvérsias envolvidas na definição dos termos direita e esquerda (Taroco; Madeira, 2013; Cruz, 2015), parece-nos pertinente a ideia de que o projeto da esquerda - em suas diversas manifestações, linguagens e nuances - busca questionar desigualdades que considera injustificadas, mas que são em geral encaradas como sagradas, naturais ou inevitáveis pela direita (Cruz, 2015; Lukes, 2003). Isso posto, acreditamos que, de alguma forma, a diferenciação entre essas linhas de pensamento - que servem de base para as narrativas dos jovens participantes da pesquisa -, podem auxiliar na compreensão do cenário político brasileiro na atualidade.

Ao analisar os diferentes protestos de natureza política ocorridos no país na última década, Tatagiba e outros (Tatagiba, 2018; Tatagiba; Trindade; Teixeira, 2015) identificam um movimento crescente que vem sendo protagonizado pela direita desde 2007 , e que teve na campanha pelo impeachment da presidente Dilma Rousseff, em 2016, uma de suas maiores expressões. Trata-se de grupos e de organizações, sem tradição de militância e ocupação dos espaços públicos em protestos, que passam a se fazer cada vez mais presentes, defendendo pautas cujo núcleo discursivo e simbólico está centrado no regime político - manifesto na luta contra a corrupção e no ódio ao Partido dos Trabalhadores (PT) - e na autoridade - enfocando, sobretudo, os temas da defesa da família e da ordem, inclusive com apelos ao retorno do regime militar. Pode-se dizer que o mote catalisador desta dinâmica gira em torno da "indignação com a corrupção das instituições da democracia, seletivamente dirigida ao PT, conformando um antipetismo com forte apelo nas ruas" (Tatagiba, 2018: 93, grifo da autora). Além da própria campanha em favor do impeachment, destacam-se os panelaços e as várias manifestações que traziam como palavras de ordem "Fora PT", "Fora 
Dilma" e "Fora CorruPTos". Em sua maioria, os organizadores estavam vinculados a movimentos constituídos ao longo deste período, como o "Vem Pra Rua", "Revoltados On-line" e "Movimento Brasil Livre" - todos com forte atuação nas redes sociais e em grande parte protagonizados por jovens (Gohn, 2018; Tatagiba, 2018; Tatagiba; Trindade; Teixeira, 2015).

É fato que tais eventos trouxeram grandes implicações nos debates políticos, acirrando disputas entre diferentes grupos e setores da sociedade, repercutindo não apenas nas composições partidárias e eleitorais, como também nas relações cotidianas das pessoas. São essas implicações que os jovens de nossa pesquisa identificam como sendo a polarização entre direita e esquerda:

A gente vive hoje no Brasil [...] uma polarização de esquerda e direita demonizada. [...] Não tem como ser neutro. (Rodrigo, História, Paranaguá).

Parece que o mundo se dividiu entre direita e esquerda. (Beatriz, História, Campo Mourão).

[Sobre a relação entre o curso de Graduação e a política] normalmente elas são concentradas mais por um viés de esquerda, e a maioria dos movimentos de esquerda não são coisas que eu concordo. (Wagner, História, União da Vitória).

Importante ressaltar que não há uma unanimidade no posicionamento dos estudantes - ainda que vários deles façam a defesa do viés de esquerda, que também seria, segundo eles próprios, priorizado por seus cursos de Graduação -, havendo participantes que se declaram abertamente em favor do que entendem ser de direita. A propósito, a constatação de tal diversidade de posicionamentos, de certa forma, coloca em análise um entendimento que associa a educação pública - especialmente os conteúdos das Ciências Humanas - a uma possível doutrinação político-ideológica por parte dos professores (Frigotto, 2017; Ação Educativa, 2016).

Outro ponto a ser destacado com relação a esta categoria temática é a ideia de política associada a embates, tensões e conflitos, decorrentes de posicionamentos antagônicos defendidos pelas pessoas. Na visão dos jovens, os desentendimentos implicados no debate político são vistos como indesejados, já que levariam a esgarçar as sociabilidades estabelecidas em seu cotidiano, seja na família, em sala de aula ou no trabalho.

Segundo McAdam, Tarrow e Tilly (2009), nem toda política implica em confronto, o qual se faria presente apenas diante de reivindicações de grupos cujas 
pautas ameaçariam outros grupos. De modo análogo, autores como Jürgen Habermas e John Rawls enaltecem a importância do consenso - obtido com base na racionalidade - como ponto de chegada das interações entre os sujeitos, o que possibilitaria a vida em comum (Miguel, 2014; Lois, 2005; Lima, 1993). Para além deste pensamento que entende a política e a democracia como o exercício racional em busca do consenso (Mendonça; Vieira Jr., 2014; Machado, 2013), há ainda, na literatura, autores que compreendem a política como um campo necessariamente permeado por conflitos, dissensos e disputas. É o caso, por exemplo, de teóricos como Hannah Arendt, Ernesto Laclau e Jacques Rancière, os quais, ainda que fundamentados em perspectivas teóricas divergentes, entendem 0 conflito como elemento inerente à política, que adquire um caráter reivindicatório e contra-hegemônico, não apenas no plano teórico como também no da práxis (Fair, 2009; Machado, 2013). Nesse sentido, concordamos com Miguel (2014), para quem o conflito é próprio da política e, uma vez que sua intensificação pode trazer entraves à vida em sociedade, faz-se necessária a busca por uma unidade mínima que possibilite a convivência. Ainda assim, segundo o autor, “o reconhecimento da importância dessa preocupação não elimina o antagonismo das disputas políticas, nem o fato de que as regras e procedimentos não são neutros em relação aos grupos e interesses em choque" (Miguel, 2014: 15).

Este entendimento - que vemos como adequado para a compreensão da dinâmica política, em especial no Brasil - parece indicar uma outra direção daquela sugerida pelos jovens da pesquisa, uma vez que, para estes, os debates políticos comprometem a convivência entre as pessoas, pois envolvem brigas e desentendimentos que deveriam ser evitados ou minimizados: "não tem como discutir com ele [...] não há convergência de ideias"; "A gente briga muito e estraga o almoço de todo mundo. [...] Não vai adiantar a gente ficar ali se matando"; "eu fico bem longe desse tipo de coisa, [...] não mostro minha opinião porque daí já começa a brigar". Como vemos, esta compreensão defendida pelos estudantes - que, em última instância, parecem atuar no sentido de suprimir ou evitar os conflitos na vida coletiva - acaba por trazer implicações para o modo como se posicionam: diante da inevitabilidade da tensão, os jovens optam por se afastar dos embates e dos conflitos, deixando em segundo plano os assuntos que envolvam questões políticas.

\section{Política e formas de participação}

Todos os jovens da pesquisa referiram-se, de algum modo, a esta categoria temática, que traz a política associada a diferentes formas de participação na vida pública, como podemos constatar no Quadro 4, a seguir. 
Quadro 4: Política e formas de participação - sentidos e narrativas dos jovens

\begin{tabular}{|c|c|}
\hline Descrição & Trechos das narrativas \\
\hline $\begin{array}{l}\text { Nesta categoria temática, o sentido de } \\
\text { política refere-se à participação na vida } \\
\text { pública, que pode se dar de diferentes formas, } \\
\text { abrangendo tanto as instâncias do Estado } \\
\text { - partidos políticos, campanhas e eleições } \\
\text { nas diferentes esferas de poder - quanto } \\
\text { outras vias de ação, como o envolvimento } \\
\text { em grupos estudantis, greves e outros } \\
\text { movimentos políticos. Os jovens enfatizam } \\
\text { distintos modos de participação, que podem } \\
\text { se dar por meio da escolha de representantes } \\
\text { ou mesmo pelo engajamento do próprio } \\
\text { sujeito em manifestações coletivas. Nessa } \\
\text { direção, um primeiro sentido que emerge } \\
\text { das narrativas é o da política como espaço } \\
\text { de representação, de modo que a política } \\
\text { aparece diretamente relacionada ao direito } \\
\text { de escolha, sobretudo às eleições para } \\
\text { as instâncias executivas e legislativas do } \\
\text { Estado. O significado da política se expressa } \\
\text { pelo envolvimento em campanhas e/ou } \\
\text { pelo exercício do voto - que, a propósito, } \\
\text { conforme a legislação eleitoral brasileira, é } \\
\text { obrigatório. Os mesmos sujeitos reconhecem } \\
\text { a existência de outros modos de participação } \\
\text { política, embora, em alguns casos, optem por } \\
\text { se manter afastados de tais manifestações. } \\
\text { Há, ainda, diversos jovens que relacionam } \\
\text { a política justamente ao envolvimento } \\
\text { direto - isto é, não restrito apenas à escolha } \\
\text { de representantes - em movimentos e } \\
\text { grupos políticos, como: diretório acadêmico, } \\
\text { greves, protestos, ocupaçoses de escolas } \\
\text { e universidades, entre outros. Assim, } \\
\text { quando refletem acerca da política, de seus } \\
\text { significados e de como esta impacta em suas } \\
\text { vidas, acabam por mencionar a participação } \\
\text { nos eventos citados. }\end{array}$ & $\begin{array}{l}\text { "Expor ideias e ter alguém que represente } \\
\text { você, por mais que hoje a gente não veja isso, } \\
\text { mas a política serve a isso, uma coletividade } \\
\text { e alguém que represente a voz de alguém." } \\
\text { (Rafael, História, Paranaguá). } \\
\text { ="A partir do momento em que vou ao lugar } \\
\text { de votação e voto, já estou sendo uma pessoa } \\
\text { política, votar e eleger candidatos." (Janaína, } \\
\text { Geografia, Paranavaí). } \\
\text { “[As vivências na Universidade] Incentivam } \\
\text { [a participação política] em movimentos, } \\
\text { principalmente quando aconteceram as } \\
\text { greves e paralisação aqui, ocupação. [...] Essa } \\
\text { coisa da minoria entrar para a faculdade, } \\
\text { envolve muita política, e isso faz com que } \\
\text { você entre nesse mundo, você participe } \\
\text { das passeatas que acontecem contra } \\
\text { governadores, contra políticos que querem } \\
\text { sucatear a universidade." (Luiza, História, } \\
\text { União da Vitória). }\end{array}$ \\
\hline
\end{tabular}

Fonte: Dados da pesquisa.

Ao associarem o sentido da política às formas de participação, podemos perceber dois movimentos que emergem das compreensões dos jovens da pesquisa. No primeiro deles, a política se refere ao âmbito da formalidade do Estado, girando em torno dos calendários eleitorais, e a participação dos jovens fica circunscrita à realização de campanhas e ao exercício do voto, isto é, da escolha dos representantes nas diferentes esferas - local, estadual e nacional. 
Palmeira $(2002,1996)$ sugere, com base em seus trabalhos antropológicos, que os períodos eleitorais se constituem como momentos em torno dos quais a sociedade se mobiliza, envolvendo todas as pessoas e grupos em uma dinâmica de disputas e conflito autorizado. É nesse momento - denominado pelo autor como tempo da política - que os cidadãos percebem a política fazendo parte de seu cotidiano, quando vivenciam mais intensamente as disputas implicadas no processo de escolha dos representantes. Fora deste período, isso é, no dia a dia das pessoas comuns, a política é vista como atividade própria e restrita àqueles que exercem seus mandatos no Executivo e no Legislativo. De modo análogo, Cervi (2010) compreende que, para o eleitor, isto é, para a maioria da população, o tempo da política coincide com o período eleitoral, ainda que as movimentações partidárias, a construção de alianças e as relações de poder entre os políticos se efetivem continuamente. Deste modo, o que se revela é que, de fato, a política é associada, em geral, apenas aos períodos eleitorais, sendo que a participação de grande parte dos indivíduos limita-se ao momento do voto, cabendo aos eleitos, isto é, aos "políticos", desempenhar sua função de mediadores entre a população e o Estado.

Nesta dinâmica, Castro (2016) afirma que o sistema de democracia representativa acabou por restringir ao voto a participação do cidadão junto à esfera pública, transformando-0, em última instância, em um sujeito político passivo. Nesse sentido, a "ocasional participação política por meio do voto significou o progressivo desinvestimento psíquico da maioria dos cidadãos adultos das disputas e dos embates públicos. [...] A especialistas, gestores e políticos delegou-se a tarefa de exercer o cuidado com o mundo" (Castro, 2016: 83). Com base nessa lógica, ao que sugerem nossos dados, os jovens parecem considerar suficiente exercer a participação política nos períodos eleitorais, afirmando que, em outros momentos, permanecem afastados dessa dimensão.

$\mathrm{Na}$ questão de me posicionar quanto ao voto, por exemplo, sim, porque eu tento também participar, perceber qual candidato seria melhor [...] agora, quanto a participar realmente dentro da política, eu acho que não. (Vivian, História, Campo Mourão).

[Participa de atividade que considera política?] Não, acho que não, é só ali dentro, quando tem campanha, aí vamos pedir voto e fazer campanha, mas fora isso não. (Gustavo, Geografia, Campo Mourão).

O meu pai já se candidatou para vereador aqui na cidade [...] Daí, nesse momento, eu participava, porque eu tinha que ajudar, porque era meu pai. Tinha que dar apoio, né? [...] Mas foi unicamente essa vez. (Beatriz, História, Campo Mourão). 
Por outro lado, como um segundo movimento a ser destacado com base nessa categoria temática, encontram-se os jovens que relacionam a política a uma participação engajada em movimentos e grupos, não se limitando ao exercício do voto. Trata-se, neste caso, de uma compreensão mais ampliada de política e participação, implicada no envolvimento direto do sujeito, uma vez que sua atuação não se restringe à escolha de representantes, tampouco de delegar aos mesmos a possibilidade exclusiva de agir junto à esfera pública para atender às demandas da sociedade. Embora metade dos participantes tenham mencionado expressamente que não se consideram sujeitos políticos, ou que não participam de nenhuma atividade política, outros sete apresentaram relatos que revelaram a participação e envolvimento em diferentes movimentos e grupos, como grêmio estudantil, movimento feminista, greves, a ocupação nas universidades, entre outros. Podemos conferir este sentido nos exemplos a seguir:

Eu já participei de coisa assim, tipo quando a gente estava em greve aqui, que fizeram passeata, fizeram coisa aqui na praça pela Unespar, como eu estava me sentido atingida, daí eu participei (Juliana, Geografia, União da Vitória).

Participei das ocupações. [...] Estava próximo do ENEM, então eu me propus a ministrar aula sobre ditadura militar, que é algo que sempre cai nas provas. [...] Se estiver tendo um protesto, alguma coisa, eu sempre estou lá pra falar. Eu participei da greve geral. [...] Eu participei de greve no terminal também, eu fechei o terminal por causa do aumento da tarifa. (Rodrigo, História, Paranaguá).

Cabe ressaltar que, conforme mencionaram os próprios jovens, a participação em movimentos e manifestações nem sempre se deu de modo intenso ou como resultado de uma convicção do próprio sujeito, mas sim por influência de professores e amigos: "por causa dos meus amigos, que já estavam aqui"; "o menino que entrou comigo [na faculdade] já tinha a vivência dos grêmios, então a gente bolou para fazer o diretório”. Ainda, em alguns casos, os sujeitos expressam até mesmo certa discordância para com tais movimentos: "é uma coisa que me incomoda um pouco, mas eu participei só essas vezes que teve coisa de greve".

Podemos verificar que, desde as Jornadas de Junho de 2013, a participação dos jovens brasileiros em manifestação de protestos nos espaços públicos tem se ampliado (Gohn, 2018; Castro, 2015). A propósito, após as referidas 
Jornadas - ocorridas em diferentes municípios do país -, os jovens passaram a ser vistos como o principal grupo representante do "sentimento brasileiro de indignação". Tais eventos, que se destacaram por sua amplitude, impacto e pela rapidez de sua difusão, trouxeram como características o intenso uso das mídias sociais e a ação direta dos sujeitos, que tomam os espaços públicos como palco privilegiado das manifestações, em busca de expressão e visibilidade (Barreira, 2014).

É preciso ressaltar que tais manifestações por parte da juventude nem sempre se constituem com base em uma homogeneidade nas pautas e nos posicionamentos, sendo possível observar diferentes demandas - que abrangem tanto preocupações políticas quanto sociais e morais - que são orientadas por distintas referências político-ideológicas (Gohn, 2018; Castro, 2015; Tatagiba, 2018). A participação em movimentos e grupos nem sempre decorre de uma intencionalidade lúcida e esclarecida por parte dos jovens, ou mesmo de uma trajetória de militância, mas por vezes se dão ao acaso, na esteira de um evento em curso e/ou mesmo pela influência de pessoas próximas (Castro, 2016). De todo modo, ao participarem de tais movimentos e manifestações políticas, os jovens se organizam de diferentes maneiras, buscando formas nem sempre hierarquizadas ou centralizadas na tomada de decisões, e construindo sociabilidades e laços de solidariedade e responsabilidade que influenciam no modo como passam a se posicionar diante da coletividade (Gohn, 2018; Castro, 2016).

É com este olhar, portanto, que devemos ler as experiências dos jovens de nossa pesquisa junto a movimentos e grupos, bom como às greves e ocupações das escolas e universidades, dos quais vários deles mencionam ter participado, e que passaram a fazer parte de suas compreensões acerca da dimensão política. Tal participação e engajamento não podem ser vistos apenas como resultado de uma ação motivada por valores e ideologias já construídos pelos jovens em suas trajetórias, mas são também - e em grande parte - influenciadas pelas relações interpessoais que estabelecem, assim como pelos próprios eventos ocorridos no Estado e nas universidades públicas ao longo de seu curso de Graduação.

\section{Política, conhecimento e formação universitária}

Esta última categoria temática, presente nas narrativas de 12 dos 14 jovens, apresenta um sentido de política associado ao conhecimento e à formação universitária, como podemos conferir no Quadro 5. 
Quadro 5: Política relacionada ao conhecimento e à formação universitária - sentidos e narrativas dos jovens

\begin{tabular}{|c|c|}
\hline Descrição & Trechos das narrativas \\
\hline $\begin{array}{l}\text { Nesta categoria temática, o sentido de política } \\
\text { está relacionado ao conhecimento, ao âmbito } \\
\text { da razão. A vivência e compreensão da } \\
\text { política exige estudo, visão crítica, informação, } \\
\text { embasamento e, nesse aspecto, o curso de } \\
\text { Graduação e a trajetória na Universidade } \\
\text { assumem um papel importante para esses } \\
\text { jovens, na medida em que possibilitam ir } \\
\text { além do senso comum e da ingenuidade e, } \\
\text { com base na formação recebida, questionar } \\
\text { os “discursos comprados” presentes no } \\
\text { meio social. Os jovens compreendem o } \\
\text { conhecimento como uma condição necessária } \\
\text { para a atuação política - de si mesmo, a fim } \\
\text { de saber tomar posição, quanto das outras } \\
\text { pessoas, em especial dos políticos em geral. } \\
\text { Este sentido emerge igualmente quando os } \\
\text { jovens comentam acerca de suas interações } \\
\text { com os familiares, quando eventualmente } \\
\text { conversam sobre temáticas relacionadas à } \\
\text { política, sendo que os estudantes associam } \\
\text { o grau de conhecimento e informação à } \\
\text { capacidade de debater e argumentar a respeito } \\
\text { dos assuntos e eventos políticos. Por fim, estão } \\
\text { muito presentes as narrativas relacionadas } \\
\text { ao curso de Graduação e à Universidade, que } \\
\text { aparecem como uma experiência fundamental } \\
\text { e condicionante de seus entendimentos, } \\
\text { proporcionando conhecimentos, pensamento } \\
\text { crítico e embasamentos para que esses jovens } \\
\text { compreendam a política, saibam se posicionar e } \\
\text { participar de modo consciente da sociedade. }\end{array}$ & $\begin{array}{l}\text { “é muita pessoa sem conhecimento. Creio } \\
\text { que as pessoas estão envolvidas na política } \\
\text { deveriam ter mais estudo, ter mais } \\
\text { fundamentação sobre aquilo que estão } \\
\text { fazendo, buscar observar o que acontece } \\
\text { no mundo ou no local onde vivem para } \\
\text { fazer algo de benéfico àquela região." } \\
\text { (Janaína, Geografia, Paranavaí). } \\
\text { “[Converso sobre política] com o meu } \\
\text { irmão, às vezes, só que ele não entende } \\
\text { nada. Não sabe nem o que ele está } \\
\text { falando, usa aqueles discursos comprados." } \\
\text { (Andréia, História, Paranavaí). } \\
\text { "A mãe não tem muito argumento. O pai } \\
\text { lê mais, tem mais argumento. Nessa } \\
\text { questão de política, ele lê jornal, sabe uma } \\
\text { informação que é mais maliciosa e tudo } \\
\text { mais." (Flávio, Geografia, Paranavaí). } \\
\text { "O curso também dá esses incentivos, } \\
\text { porque você tem essa visão mais } \\
\text { crítica, você percebe realmente o que } \\
\text { está acontecendo à sua volta, como que } \\
\text { está sendo levada essa questão política." } \\
\text { (Vivian, História, Campo Mourão). }\end{array}$ \\
\hline
\end{tabular}

Fonte: Dados da pesquisa.

Ao analisarmos esta categoria temática, verificamos, em primeiro lugar, que o sentido que os jovens atribuem à política dá destaque às contribuições obtidas com base na formação na universidade, pelo conhecimento e visão crítica adquiridos durante a trajetória na Graduação. Com efeito, em investigação anterior, também com jovens da Unespar, foi possível perceber que o ingresso no Ensino Superior proporcionou, na visão dos estudantes, uma compreensão mais crítica e ampla sobre a política, além de incentivar a participação dos jovens (Souza, 2019).

Conforme já expressamos em outras pesquisas (Pátaro; Mezzomo; Gallardo, 2018), concordamos com alguns autores quando afirmam que é responsabilidade 
da Universidade constituir-se como espaço público de produção de conhecimento, discussão crítica, tomada de consciência e engajamento sociopolítico (Santos, 2011; Severino, 2009; Landinelli, 2009). A formação em nível superior certamente promove modificações nas concepções dos sujeitos, podendo figurar como um elemento relevante na constituição de suas identidades, sendo o ingresso em uma Universidade um momento relevante na biografia do sujeito. $\mathrm{O}$ ambiente familiar, vivido em geral até a entrada no Ensino Superior, é confrontado com uma nova realidade de mundo proporcionada pelo ambiente universitário, colocando muitas vezes em cheque as compreensões, valores e comportamentos adquiridos junto à família (Oliveira; Panasiewicz, 2014). Neste sentido, entendemos que tais mudanças podem promover também transformações na visão de mundo e nas concepções dos jovens que passam a vivenciar 0 ambiente universitário.

Nesta direção, é possível entender que a formação em nível superior pode promover diálogos e reflexões que influenciam o modo como os sujeitos lidam com as mensagens políticas e culturais que recebem, e, consequentemente, na forma como passam a intervir. Ainda que suas ações possam ser limitadas por situações estruturais - condição socioeconômica, acesso a bens e serviços, entre outros -, os jovens têm a possibilidade de agir com base em sua interpretação do contexto em que está inserido (Alonso, 2004). De certa forma, esta é a perspectiva que parece permear o sentido que os estudantes da pesquisa atribuem à política nesta categoria temática.

Por outro lado, é preciso consideramos que a compreensão dos jovens reforça, ao mesmo tempo, a ideia de que a ação política estaria restrita aos sujeitos esclarecidos, detentores do conhecimento, da razão e do pensamento crítico. Esta visão, de alguma forma, remonta ao entendimento dado por Kant (2005) um dos representantes do Iluminismo europeu - ao alvorecer da modernidade, quando defende que o esclarecimento - que também pode ser compreendido como a racionalidade do indivíduo - seria condição essencial para a autonomia moral e intelectual, isto é, para a superação do estado de menoridade, de tutoria e dependência.

Este é justamente o raciocínio que sustenta a noção do homem público do iluminismo, cuja construção se ancora no princípio universal de regulação institucional e individual, na secularização e na racionalização (Castro, 2016). Ainda segundo Castro, com base nessas premissas, características da modernidade, o espaço público, em contraposição ao mundo privado, passa a ser destinado às discussões acerca do bem comum, e o exercício da cidadania plena implica uma preparação cognitiva, emocional e moral. Tal modelo de constituição do sujeito 
público - influenciado pelas práticas europeias oitocentistas e igualmente pelas considerações de teóricos como Durkheim - passou a ser visto como único e universal, orientando a formação de indivíduos livres, racionais e civilizados, que apenas quando adultos se tornariam capazes de atuar na vida pública e nas questões políticas. Como consequência de tal entendimento, às crianças e aos jovens passou a ser reservado um processo de preparação, apartado da vida pública, e amparado por instituições como a família e a escola, nas quais esses sujeitos - ainda em formação e incapazes de participar da esfera pública - deveriam ser protegidos das tensões e conflitos da sociedade. Essa é, inclusive, a defesa de Arendt $(2002,2007)$, para quem a instituição escolar não deveria se constituir como um espaço público e político, já que os debates e conflitos deveriam ser prerrogativa apenas do mundo adulto. Diante do exposto, é fato que tal perspectiva traz certas dificuldades para pensarmos as relações entre juventude e política, uma vez que aos jovens - ainda imaturos, despreparados e pouco críticos - não caberia a possibilidade de participação política.

Nesse sentido, a perspectiva dos estudantes participantes da pesquisa parece sugerir que o ingresso na Universidade os autoriza e os capacita - com o capital cultural e as regras necessárias - para a atuação no campo político (Bourdieu, 2011), reforçando a ideia de que o conhecimento e a razão devem ser uma condição para a boa política, que não pode ser exercida por todos, senão por aqueles que possuem o esclarecimento. É assim, por exemplo, que a Universidade - também tomada como lócus do conhecimento - parece ser, segundo os jovens, um espaço mais apropriado aos debates políticos do que o âmbito familiar, já que este último é marcado pela convivência com pessoas menos estudadas, sem argumentos e suscetíveis ao senso comum, aos discursos enganosos e à manipulação pelas mídias.

\section{Considerações finais}

Ao olharmos para os diferentes sentidos que os jovens atribuem à política, consubstanciados nas cinco categorias temáticas construídas, é possível problematizar de que forma esses sujeitos compreendem e lidam com a dimensão pública, com a coletividade e com os princípios e valores tidos como relevantes e que deveriam ser comuns a toda a sociedade. Para os jovens da pesquisa, a dimensão política aparece relacionada, ao mesmo tempo, ao espaço público para a construção do bem comum; aos interesses particulares e corrupção; ao debate, à manifestação de ideias e aos posicionamentos; à participação; e ao conhecimento. Em cada uma dessas facetas, podemos perceber, simultaneamente, 
as influências das condições subjetivas e dos eventos e dinâmicas que marcam o contexto mais amplo.

Deste modo, fica ressaltada uma grande diversidade nas compreensões dos estudantes, seja em relação às concepções acerca da política, às formas de ação e participação na sociedade, ao posicionamento político que expressam, ou mesmo às influências proporcionadas pelo curso de Graduação. Com efeito, o que percebemos é um mosaico de sentidos, que abarcam consensos e contradições, e que são construídos com base em diferentes trajetórias e das múltiplas influências que cada jovem recebe com base em seus espaços de sociabilidade. Não há, portanto, como separar as compreensões dos sujeitos jovens do contexto ao qual estas se articulam e no qual se constituem, de modo que a dicotomia entre sujeito e objeto, indivíduo e sociedade parecem não ser apropriadas para o entendimento das dinâmicas contemporâneas, em especial no que tange à relação entre juventude e política (Mayorga, 2013; Latour, 2012).

Diante disso, há que se questionar os estereótipos construídos - em parte pela própria literatura, reforçada pelo imaginário social - que compreendem os jovens como apáticos ou afastados das discussões da vida pública, ou mesmo que associa o ingresso na Universidade a uma maior participação e engajamento político (Mayorga, 2013; Boghossian; Minayo, 2009). Ainda, os diversos sentidos que os jovens atribuem à política deixam claro que não se pode mais considerar a participação apenas com base nas vias tradicionais ou nas formas institucionais de organização do Estado, mas que há outros espaços, relações e debates que são articulados e compreendidos como sendo parte da dimensão política.

No entendimento dos jovens participantes, as compreensões acerca da política são embasadas pelos significados que atribuem a elementos como a coletividade, a atuação do Estado e de seus representantes, os conflitos presentes nas relações interpessoais, o alcance das ações dos sujeitos nos espaços e debates públicos, o pensamento crítico e as relações de poder, entre outros. Os sentidos atribuídos à política aqui sistematizados trazem implicações que, em alguns casos, favorecem a aproximação do jovem à dimensão pública e coletiva, à discussão e às disputas pelo bem comum e, em outros casos, conduzem a um distanciamento, ou mesmo a certa passividade e aceitação da realidade. De modo análogo, algumas das compreensões reforçam a ideia de que a política se constitui como uma dimensão restrita a determinados indivíduos e a determinados tipos de organização e relação, enquanto outras potencializam o engajamento efetivo de todos, em diferentes formas e espaços, nas decisões coletivas da sociedade. De toda forma, a análise e interpretação de nossos 
dados sugerem que não é possível compreender a constituição do sujeito político como um processo linear e contínuo - como apregoava o ideal iluminista do homem público -, isto é, de uma condição de inaptidão e de imaturidade para um estado de maior racionalidade, conhecimento e criticidade, tipo ideal que se pretenderia universal. A multiplicidade que marca os entendimentos dos jovens, bem como os diversos fatores e influências que se configuram na relação entre sujeito e meio social nos levam a ressaltar tal processo como algo muito mais complexo e dinâmico. Além disso, é fato que não se pode associar a participação dos jovens e o engajamento em movimentos e manifestações a ideais transformadores e emancipatórios atribuídos em geral a grupos de esquerda, inclusive pela onda crescente de manifestações em uma perspectiva de direita, como podemos verificar nos últimos anos no Brasil (Tatagiba, 2018; Tatagiba; Trindade; Teixeira, 2015; Castro, 2015). O que pudemos depreender de nossos dados foi, ao mesmo tempo, a existência de jovens que participam de tais eventos por motivações político-ideológicas - de espectros distintos -, como também daqueles que acabam se envolvendo por razões circunstanciais, em busca de estar com seus pares e com eles compartilhar emoções e vivências (Castro, 2016), levados pelos acontecimentos e relações próprios dos espaços que frequentam, como foi o caso dos movimentos nacionais contra a corrupção de políticos, ou voltados ao impeachment da presidente, ou mesmo das greves e ocupações que marcaram o cenário da educação paranaense ao longo da trajetória desses jovens no Ensino Superior.

Assim, ao que parece, o processo de constituição do sujeito político - isto é, do modo como os indivíduos se posicionam diante da dimensão pública e dos valores que devem ser comuns a toda a sociedade - se dá com base em uma multiplicidade de fatores e eventos, de modo nem sempre previsível e ao longo das vivências e das trajetórias dos sujeitos, que vão, nas relações que constroem e que estabelecem em seu cotidiano, (re)dimensionando suas convicções pessoais em vista das demandas e valores compartilhados coletivamente (Castro, 2016; Boltanski, 2014; 2017). Desse modo, os sentidos que atribuem à política, bem como as estratégias de participação na vida pública por parte dos jovens não são decorrentes necessariamente de um conjunto de princípios e pautas previamente construídos e acionados de modo racional, mas representam uma dinâmica complexa de experimentações que o sujeito efetiva no convívio com as demais pessoas e grupos da sociedade.

Por fim, vale termos presente a onda crescente de movimentos e pautas que parecem colocar em cheque algumas das conquistas da democracia no campo dos direitos humanos - e que parecem desestabilizar o papel do Estado e as 
noções de democracia e de cidadania -, assim como a visibilidade e protagonismo que os jovens vêm ganhando nas atuais manifestações políticas ocorridas no Brasil, seja em busca de questionar ou de legitimar, de alguma forma, desigualdades e privilégios (Cruz, 2018; Lukes, 2003). Diante disso, argumentamos acerca da necessidade de aprofundar nosso olhar para as vivências, os significados e as relações que os jovens - vistos até pouco tempo como sujeitos "excluídos" da política (Castro, 2016; Arendt, 2002; 2007) - constroem com seus pares no fazer cotidiano, bem como de problematizar os espaços de formação, institucionalizados ou não, junto aos quais esses jovens constituem suas trajetórias, incluindo a própria Universidade.

\section{Referências}

AÇÃO EDUCATIVA (Org.). A ideologia do movimento Escola Sem Partido: 20 autores desmontam o discurso. São Paulo, Ação Educativa, 2016.

ALONSO, Osvaldo. La lógica de los actores y el desarrollo local. Pilquen, Viedma, n. 6, 2004, pp. 50-65.

ARENDT, Hannah. O que é política? Rio de Janeiro, Bertrand Brasil, 2002. A condição humana. Rio de Janeiro, Forense Universitária, 2007.

ARISTÓTELES. A Política. 2. ed. São Paulo, Martins Fontes, 1998.

BARDIN, Laurence. Análise de conteúdo. 6 ed. Lisboa, Edições 70, 2011 (280).

BARREIRA, Irlys Alencar F. Ação direta e simbologia das "jornadas de junho": notas para uma sociologia das manifestações. Contemporânea, São Carlos, v. 4, n. 1, jan./ jun. 2014, pp. 145-164.

BAUMAN, Zygmunt. Em busca da política. Rio de Janeiro, Zahar Editora, 2000 (216). A sociedade individualizada. Rio de Janeiro, Zahar Editora, 2008 (324).

BOGHOSSIAN, Cyntia; MINAYO, Maria Cecília. Revisão sistemática sobre juventude e participação nos últimos 10 anos. Saúde e Sociedade, São Paulo, v. 18, n. 3, 2009, pp. 411-423.

BOLTANSKI, Luc. Uma crítica para o presente. Entrevista concedida a Camila Gui Rosatti, Eduardo Vilar Bonaldi e Mariana Toledo Ferreira. Plural, São Paulo, v. 21, n. 1, 2014, pp. 217-230.

Questionando a realidade. Diálogo Global, v. 7, n. 1, 2017, pp. 8-10. Disponível em: <http://isa-global-dialogue.net/wp-content/uploads/2017/03/vii1-portuguese. pdf $>$. Acesso em: 16 set. 2019.

BOURDIEU, Pierre. O campo político. Revista Brasileira de Ciência Política, Brasília, n. 5, jan./jul. 2011, pp. 193-216.

CASTELLS, Manuel. Ruptura: a crise da democracia liberal. Rio de Janeiro, Zahar, 2018 (152). 
CASTRO, Lucia Rabello. Reflexões sobre juventude brasileira e engajamento político-social. Entrevista concedida a Thaís Serafim e Lara Grigoletto Bonini. Revista NUPEM, Campo Mourão, v. 7, n. 12, 2015, pp. 11-19.

Subjetividades públicas juvenis: a construção do comum e os impasses de sua realização. Estudos de Psicologia, Natal, v. 21, n. 1, jan./mar. 2016, pp. 80-91.

CERVI, Emerson Urizzi. O “Tempo da política” e a distribuição de recursos partidários: uma análise do HGPE. Revista em Debate, Belo Horizonte, v. 2, n. 8, 2010, pp. 12-17.

CORROCHANO, Maria Carla; DOWBOR, Monika; JARDIM, Fabiana. Juventudes e participação política no Brasil do século XXI: quais horizontes? Laplage em Revista, Sorocaba, v. 4, n. 1, jan./abr. 2018, pp. 50-66.

CRUZ, Sebastião Velasco. Elementos de reflexão sobre o tema da direita (e esquerda) a partir do Brasil no momento atual. In: CRUZ, Sebastião Velasco; KAYSEL, André; CODAS, Gustavo (Orgs.). Direita, volver!: o retorno da direita e o ciclo político brasileiro. São Paulo, Editora Fundação Perseu Abramo, 2015, pp. 13-47.

FAIR, Hernan. Arendt, Laclau, Rancière: tres teorías filosóficas de la política para pensar, comprender y modificar el mundo actual. Daimon: Revista Internacional de Filosofía, Murcia, n. 48, 2009, pp. 97-116.

FERREIRA, Bernardo. O risco do Político: crítica ao liberalismo e teoria política no pensamento de Carl Schmitt. Belo Horizonte, Editora UFMG, 2004 (339).

FRIGOTTO, Gaudêncio (Org.). Escola "Sem" Partido: esfinge que ameaça a educação e a sociedade brasileira. Rio de Janeiro, UERJ, 2017 (144).

GOHN, Maria da Glória. Jovens na política na atualidade - uma nova cultura de participação. Caderno CRH, Salvador, v. 31, n. 82, jan./abr. 2018, pp. 117-133.

IBGE Cidades. Portal eletrônico. Disponível em: <https://cidades.ibge.gov.br/>. Acesso em: 16 set. 2019.

JINKINGS, Ivana; DORIA, Kim; CLETO, Murilo (Orgs.). Por que gritamos golpe?: para entender o impeachment e a crise. São Paulo, Boitempo, 2016 (176).

KANT, Immanuel. Resposta à pergunta: Que é esclarecimento? Textos Seletos. 3. ed. Petrópolis: Vozes, 2005, pp. 63-71.

LANDINELLI, Jorge. Las finalidades públicas de la universidad en el contexto de la globalización. In: GENTILI, Pablo. (et al.). Políticas de privatización, espacio público y educación en América Latina. Rosário, Homo Sapiens Ed., 2009, pp. 205-224.

LATOUR, Bruno. Reagregando o social: uma introdução à teoria do ator-rede. Salvador, EdUFBA; Bauru, Edusc, 2012.

LOIS, Cecília Caballero. A filosofia constitucional de John Rawls e Jürgen Habermas: um debate sobre as relações entre sistemas de justiça e sistemas de direitos. Revista Seqüência, n. 50, jul. 2005, pp. 121-141. 
LIMA, Luiz Antonio de Oliveira. Alternativas éticas ao neo-liberalismo: as propostas de Rawls e Habermas. Lua Nova, São Paulo, n. 28-29, abr. 1993, pp. 335-350.

LUKES, Steven. Epilogue: the grand dichotomy of the twentieth century. In: BALL, Terence; BELLAMY, Richard. (Eds.). The Cambridge history of twentieth-century political thought. Cambridge, Cambridge University Press, 2003, pp. 602-626.

MACHADO, Frederico Viana. Subjetivação Política e Identidade: contribuições de Jacques Rancière para a Psicologia Política. Psicologia Política, São Paulo, v. 13, n. 27, maio/ago. 2013, pp. 261-280.

MAYORGA, Claudia. Pesquisar a juventude e sua relação com a política - notas metodológicas. Estudos de Psicologia, Natal, v. 18, n. 2, abr./jun. 2013, pp. 343-350.

Por novas instituições, por uma nova política: o protagonismo dos jovens no Brasil. Entrevista concedida a Ada Fontanella e Laiza Campos. Educação e Linguagens, Campo Mourão, v. 6, n. 10, jan./jun. 2017, pp. 11-24.

MCADAM, Doug; TARROW, Sidney; TILLY, Charles. Para mapear o confronto político. Lua Nova, São Paulo, n. 76, 2009, pp. 11-48.

MENDONÇA, Daniel; VIEIRA JUNIOR, Roberto. Rancière e Laclau: democracia além do consenso e da ordem. Revista Brasileira de Ciência Política, Brasília, n. 13, jan./ abr. 2014, pp. 107-136.

MIGUEL, Luis Felipe. Consenso e conflito na teoria democrática: para além do "agonismo". Lua Nova, São Paulo, n. 92, 2014, pp. 13-43.

MÜXEL, Anne. Jovens dos anos noventa: à procura de uma política sem "rótulos". Revista Brasileira de Educação, Rio de Janeiro, n. 5/6, maio/dez. 1997, pp. 151-166.

OLIVEIRA, Pedro de Assis Ribeiro; PANASIEWICZ, Roberlei. Tendências religiosas entre a população universitária: um estudo de caso. Horizonte, Belo Horizonte, v. 12, n. 36, out./dez. 2014, pp. 1160-1186.

PALMEIRA, Moacir. Política, Facções e Voto. In: PALMEIRA, Moacir; GOLDMAN, Marcio (Orgs.). Antropologia, voto e representação política. Rio de Janeiro, Contra Capa Livraria, 1996, pp. 41-56.

PALMEIRA, Moacir. Política e tempo: nota exploratória. In: PEIRANO, Mariza (Org.). $O$ dito e o feito: ensaios de antropologia dos rituais. Rio de Janeiro, Ed. Relume Dumará, 2002, pp. 171-178.

PÁTARO, Cristina Satiê de Oliveira; MEZZOMO, Frank Antonio; MILANES, Olga Alicia Gallardo. Política, religião e desenvolvimento: compreensões de jovens universitários do Brasil e de Cuba. São Paulo, Pimenta Cultural, 2018.

PEREIRA, Luis Fernando Lopes; ALLAN, Nasser Ahmad (Orgs.). 29 de Abril: repressão e resistência. Bauru, Canal 6/Projeto Editorial Práxis, 2016.

RANCIÈRE, Jacques. O desentendimento: política e filosofia. São Paulo, Editora 34, 1996. . Política, policía, democracia. Santiago, LOM Ed., 2006. 
SANTOS, Boaventura de Souza. A Universidade no século XXI: para uma reforma democrática e emancipatória da Universidade. 3. ed. São Paulo: Cortez, 2011 (120).

SEVERINO, Antonio Joaquim. Expansão do Ensino Superior: contextos, desafios, possibilidades. Avaliação, São Paulo, v. 14, n. 2, jul. 2009, pp. 253-266.

SOUZA, Leonardo Carvalho. "Um assunto meio forte": os sentidos da política para jovens universitários. Dissertação (Mestrado em Sociedade e Desenvolvimento). Universidade Estadual do Paraná, Campo Mourão, 2019.

TAROUCO, Gabriela da Silva; MADEIRA, Rafael Machado. Partidos, programas e o debate sobre esquerda e direita no Brasil. Sociologia e Política, Curitiba, v. 21, n. 45, mar. 2013, pp. 149-165.

TATAGIBA, Luciana. Os protestos e a crise brasileira: um inventário inicial das direitas em movimento (2011-2016). In: ALMEIDA, Ronaldo; TONIOL, Rodrigo (Orgs.). Conservadorismos, fascismos e fundamentalismos. Campinas, Ed. Unicamp, 2018, pp. 87-116.

TATAGIBA, Luciana; TRINDADE, Thiago; TEIXEIRA, Ana Claudia Chaves. Protestos à direita no Brasil (2007-2015). In: CRUZ, Sebastião Velasco; KAYSEL, André; CODAS, Gustavo (Orgs.). Direita, volver!: o retorno da direita e o ciclo político brasileiro. São Paulo, Editora Fundação Perseu Abramo, 2015, pp. 197-212.

Recebido em: 05/04/2019

Aprovado em: 25/11/2019

\section{Como citar este artigo:}

PÁTARO, Cristina Satiê de Oliveira e MEZZOMO, Frank Antonio. Multiplicidade, dinâmicas e relações: sentidos da política para jovens universitários. Contemporânea - Revista de Sociologia da UFSCar, v. 9, n. 2, maio - agosto 2019, pp. 351-377. 